\title{
DINÂMICA ANTRÓPICA NO CANAL FLUVIAL DO CÓRREGO TUCUM - SÃO PEDRO, SÃO PAULO (BRASIL)
}

\section{ANTHROPOGENIC DYNAMICS ON THE TUCUM STREAM'S FLUVIAL CHANNEL - SÃO PEDRO, SÃO PAULO (BRAZIL)}

\author{
Éverton Vinícius Valezio \\ Departamento de Geografia, Universidade Estadual de Campinas \\ Rua João Pandiá Calógeras, 51, Campinas, São Paulo, CEP:13087-870, Brasil \\ Email: evertonvalezio@ige.unicamp.br \\ Archimedes Perez Filho \\ Departamento de Geografia, Universidade Estadual de Campinas \\ Rua João Pandiá Calógeras, 51, Campinas, São Paulo, CEP:13087-870, Brasil \\ Email: archi@ige.unicamp.br
}

Informações sobre o Artigo

Data de Recebimento: $12 / 06 / 2015$

Data de Aprovação: 26/08/2015

\section{Palavras-chave:}

Geomorfologia fluvial; Perfil longitudinal; LOE (Luminescência Opticamente Estimulada).

\section{Keywords:}

Fluvial Geomorphology; Longitudinal Profile; Optically Stimulated Luminescence (OSL).

\section{Resumo:}

Transformações na morfologia da paisagem sempre foram constantes ao longo do tempo da natureza. Formas e processos, que até então se ajustavam naturalmente, passam a reconhecer no homem um novo agente reorganizador capaz de alterar o balanço de energia e matéria e, consequentemente, o equilíbrio dinâmico dos Geossistemas. O distúrbio das variáveis físicas e o consequente limiar de reajuste do sistema encontram nos canais fluviais elemento fundamental para o entendimento das relações do sistema antrópico com o sistema natural, repercutindo em suas formas as alterações advindas desta relação. Nesse sentido, o estudo proposto, com base na concepção sistêmica e na teoria do equilíbrio dinâmico, se justifica pela capacidade do homem potencializar os processos até então ditos naturais. Visouse identificar e interpretar as transformações ocasionadas pela ação antrópica do canal fluvial do córrego Tucum, município de São Pedro - SP, por meio da interpretação de cartas topográficas (escala 1:10.000), fotografias aéreas (1962 e 2000, escalas aproximadas de 1:25.000 e 1:30.000, respectivamente), trabalhos de campo e utilização de técnicas de datação por LOE (Luminescência Opticamente Estimulada), a fim de estabelecer uma relação de mudança entre os dois momentos das imagens não orbitais, tanto entre a disposição do uso e ocupação da terra e sua influência na configuração do córrego nos últimos cinquenta anos, quanto as idades dos depósitos sedimentares presentes nas formas adjacentes ao canal fluvial estudado. Constatou-se que as modificações de uso da terra, especialmente o estabelecimento de $16 \%$ da área da bacia em montante para fixação residencial urbana e consequente ampliação das áreas de solo exposto, foram determinantes para modificações no córrego Tucum, assumindo padrão entrelaçado em grande 
parte de seu curso. Além disso, as datações absolutas e sua distribuição espacial reportam ritmo diferenciado de elaboração da paisagem, apontando idades absolutas referentes ao Pleistoceno Superior e Holoceno.

\begin{abstract}
:
Alterations in landscape morphology have always been constant in nature over time. The forms and processes, which until then naturally self-adjusted, start to recognize man as a new reorganizing agent, capable of changing the energy and matter balance and thus, the dynamic equilibrium of the Geosystems. The physical variable disturbance and the consequent system readjustment threshold have on fluvial channels an essential element for the comprehension of the relations between the anthropic and the natural systems, since their shape reveals the alterations caused by these relations. Therefore, the proposed study, based on the systemic concept and on the theory of dynamic equilibrium is justified by man's ability to enhance processes which used to be natural. Its objective was the identification and transformations caused by anthropic action at the fluvial channel of Tucum stream, in the municipality of São Pedro, SP, based on the interpretation of topographic maps (scale 1:10.000), aerial photos (1962 and 2000, approximate scales of 1:25.000 e 1:30.000 respectively), fieldworks and the use of dating techniques by OSL (Optically Stimulated Luminescence), so as to establish a relationship of change between the two moments of non-orbital images, as much between the disposition of land use and occupation and its influence on the configuration of the stream over the last 50 years, as the ages of the sedimentary deposits present in the forms, adjacent to the fluvial channel studied. It was found that the modifications caused by the land use, especially the establishment of $16 \%$ of the upstream basin area for urban residential setting and consequent expansion of exposed soil areas, produced the changes in Tucum stream, which assumed an interlaced pattern in a large portion of its course. In addition, absolute dating and their spatial distribution report a differentiated pace of landscape development, defining absolute ages, referring to the Late Pleistocene and Holocene.
\end{abstract}

\section{Introdução}

A dinâmica de elaboração do modelado se materializa no conjunto de formas e processos que incorporam à paisagem características únicas. Dessa forma, canais fluviais se comportam como agentes principais na configuração do relevo, especialmente em bacias hidrográficas, cujas influências estrutural, litológica, pedológica, climática e, mais atualmente, antropogênica, dão a estas uma concepção sistêmica. Segundo Suguio e Bigarella (1979), os fatores climáticos parecem ser os condicionantes de sua formação, enquanto que os tectônicos contribuiriam para acentuar ao longo do tempo as diferenças entre os níveis de terraços. Desse modo, terraços fluviais e planícies de inundação se constituem como importantes mantenedores de material sedimentar - depósitos capazes de registrar características evolutivas tanto do canal fluvial, quanto dos aspectos climáticos e tectônicos circundantes (LITCHFIELD e BERRYMAN, 2005; SALLUN e SUGUIO, 2006; BRIDGLAND; WESTAWAY, 2008; GIBBARD e LEWIN, 2009).

A compreensão sistêmica entre a presença de depósitos quaternários e os processos de sua origem perpassa os padrões estabelecidos pela drenagem local, capazes de fornecer condições de sua manutenção ou, em virtude de parâmetros de gradiente e substrato litológico, seu transporte pelo sistema. Reitera-se assim a importância das discussões sobre tipologias dos canais fluviais (LEOPOLD e WOLMAN, 1957; LEOPOLD et al., 1964; SUGUIO e BIGARELLA, 1979; CHRISTOFOLETTI, 1981; MORISAWA, 1985; ROSGEN, 1994; CUNHA, 1998; entre outros), evidenciando os diversos processos presentes.

Diversas formas apresentam-se ao longo desses canais, desde bancos aluvionares presentes em canais entrelaçados e meandrantes denotando sua dinâmica atual, até terraços aluvionares que marcam uma dinâmica pretérita. Uma das formas de compreensão dessa dinâmica pode se expressar nos próprios terraços e depósitos aluviais por meio de técnicas de datação, como as efetuadas pelo método LOE (Luminescência Opticamente Estimulada), discutido inicialmente por Huntley et al. (1985) e Martin J. Aitken na década de 1980 (AITKEN e SMITH, 1988; AITKEN, 1992). Nos limites da Depressão Periférica Paulista, destacam-se as pesquisas efetuadas por Ferreira e Chang (2008) em sedimentos das formações Rio Claro e Piraçununga, e por Storani e Perez Filho (2015) em patamares sedimentares na bacia hidrográfica do rio Mogi-Guaçu, 
além dos importantes trabalhos em depósitos na unidade do Planalto Ocidental Paulista (TATUMI et al., 2006; SALLUN e SUGUIO, 2006).

Assim, objetiva-se contribuir para o entendimento da dinâmica fluvial do córrego Tucum por meio de caracterização e interpretação de suas transformações condicionadas pelos fatores natural e antrópico ao longo de seu leito principal, relacionados à dinâmica da bacia nos últimos cinquenta anos, com auxílio da datação absoluta de terraços.

\section{Materiais e Métodos}

Aárea de estudo, de acordo com a divisão proposta por Almeida (1964), se localiza na Província Geomorfológica da Depressão Periférica Paulista, na Zona de
Médio Tietê. Para Penteado (1968), essa área paleozoica se comprime entre a zona de cuesta arenito-basáltica na face oeste e o Planalto Cristalino Atlântico a leste, cujo quadro morfológico típico se dá pela suavidade de formas, com colinas de topo aplainado levemente convexas entre 550 a 600 metros e 650 a 700 metros de altitude.

O córrego Tucum nasce nos limites municipais de São Pedro, em altitudes próximas a 570 metros e nas coordenadas geográficas aproximadas $22^{\circ} 33^{\prime} 16^{\prime \prime} \mathrm{S}$ e 47 53 '38” W, escoando longitudinalmente 6000 metros até encontrar o canal do ribeirão Araquá, ainda em limites da mesma municipalidade, em altitude de 468 metros e coordenadas geográficas aproximadas de 22\%34'47”S e 47 $51^{\prime} 33^{\prime}$ 'W, possuindo área de aproximadamente 13,2 km² (Figura 1).

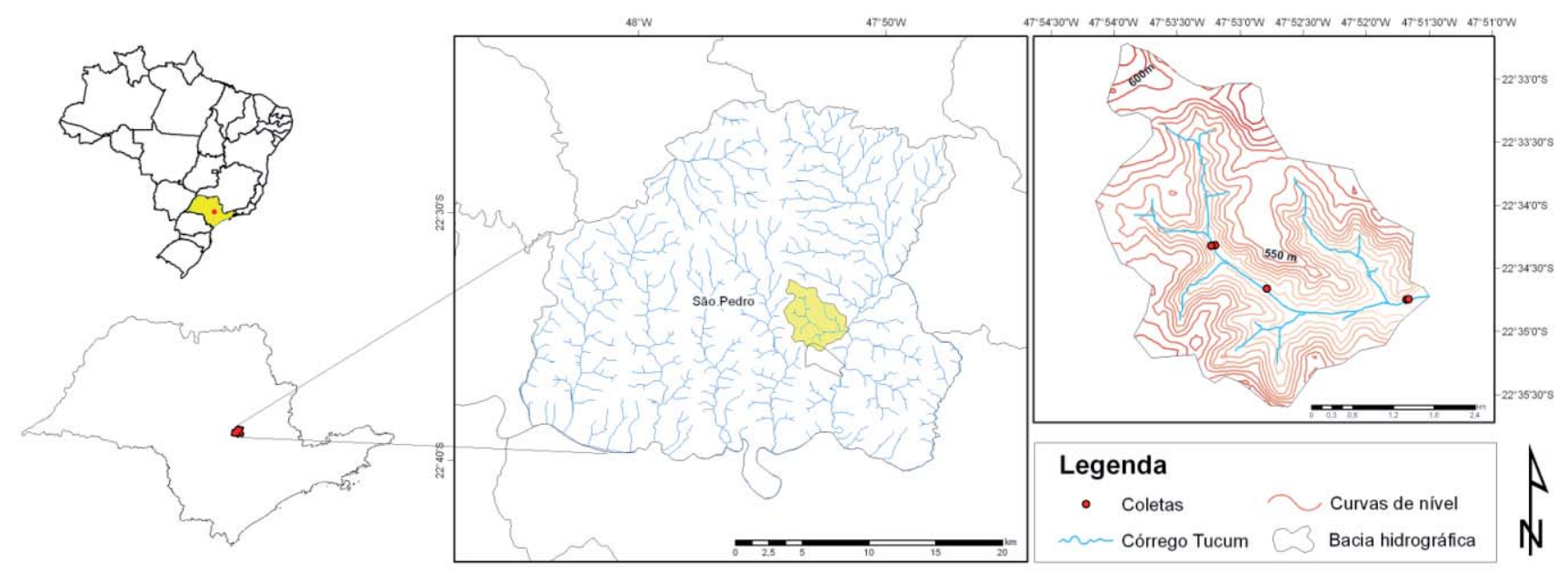

Figura 1 - Localização da bacia hidrográfica do córrego do Tucum.

Conti (1971) descreve o clima da região como um período chuvoso nos primeiros e últimos meses do ano e um período mais seco no restante do ano. Os rebordos escarpados possuem importante papel climático na área, estritamente pelas chuvas orográficas, sendo a precipitação média aproximada de 1400 mm/ano ${ }^{1}$ (DAEE).

Seus solos se caracterizam pela quantidade pronunciada de fração areia decorrente da área fonte, predominantemente arenitos da Formação Pirambóia. Em decorrência da litodependência, ganham destaque os solos com baixos níveis de ocorrência de fração argila (inferiores a 15\%), como os Neossolos Quatzarênicos, muito vulneráveis à ação denudacional (OLIVEIRA e PRADO, 1989).
O arcabouço geológico que o córrego Tucum percorre corresponde à Formação Pirambóia, que, conforme Lopes e Marconato (2006) destacam, é constituída por arenitos médios e finos com cores esbranquiçadas, avermelhadas e alaranjadas, incluindo estratificações cruzadas. Segundo Oliveira (1997), sua origem remonta a ambientes flúvio-lacustres, compreendendo um único ciclo de sedimentação, o que reflete condições climáticas quentes e úmidas que evoluiriam para condições desérticas. Para a autora, terrenos das formações Botucatu e Rio Claro também se fazem presentes na área, sendo estes relacionados, na maioria das vezes, à ocorrência de voçorocas, ravinas e sulcos no município de São Pedro.

${ }^{1}$ Dados disponíveis no website do DAEE (Departamento de Águas e Energia Elétrica), <http://<www.daee.sp.gov.br>. Acesso em 20/11/2012. 
Para a compreensão dos processos atuantes no canal fluvial, foram interpretadas quatro cartas topográficas em escala 1:10.000, referentes à área de abrangência da bacia hidrográfica do córrego Tucum, sendo elas: Ribeirão do Grama (SF-23-Y-A-IV-1-NE-C); São Pedro III (SF-23-Y-A-IV-1-NO-D); Águas de São Pedro I (SF-23-Y-A-IV-I-NO-F); e Águas de São Pedro II (SF23-Y-A-IV-1-NE-E), subsidiando também a confecção do perfil longitudinal. Para o canal fluvial estudado, foram desenhados dois perfis longitudinais, sendo um baseado nas cartas topográficas citadas e outro efetuado depois da coleta de dados in situ por meio de aparelho de GPS (Global Positioning System) e altímetro, após percorrido o canal fluvial da jusante à montante.

As fotografias aéreas não orbitais utilizadas correspondiam a dois momentos distintos, 1962 e 2000. As primeiras, em escala aproximada de 1:25.000, foram obtidas junto ao acervo do laboratório de Sensoriamento Remoto da USP (Universidade de São Paulo). As segundas, em escala aproximada de 1:30.000, foram obtidas junto à seção Ciagro (Centro de Informações Agropecuárias) da CATI (Coordenadoria de Assistência Técnica Integral) de Campinas (SP). Após as etapas de fotointerpretação, as imagens foram digitalizadas e georreferenciadas em ambiente SIG (software ArcGis 10) para vetorização. A análise comparativa entre os momentos - 1962 e 2000 - se insere na interpretação das modificações ao longo da bacia hidrográfica do córrego Tucum, tanto das características do canal fluvial quanto do uso da terra, a fim de tentar estabelecer continuidade entre essas duas dinâmicas e identificar as possíveis transformações que ocorreram ao longo desses 38 anos.

Para datações por LOE, foram coletadas cinco amostras ao longo dos terraços aluviais do canal fluvial do córrego Tucum, sendo duas localizadas no alto, margem esquerda e margem direita ( $22^{\circ} 33^{\prime} 35.48^{\prime \prime}$ 'S e $47^{\circ}$

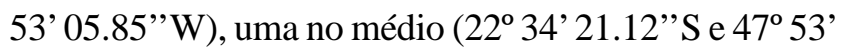

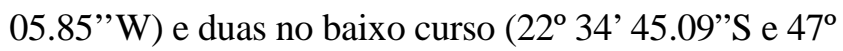
51'37.23”W), coletadas em depósitos aluviais adjacentes ao canal fluvial, sendo as amostras de alto curso retiradas a $0,75 \mathrm{~m}$ e $0,80 \mathrm{~m}$ do topo do terraço e a 1 metro do atual curso do canal (Pontos 4 e 5); a de médio curso a 0,70 $\mathrm{m}$ do topo e $0,80 \mathrm{~m}$ do canal (Ponto 3); e as de baixo curso a $0,75 \mathrm{~m}$ e 1 metro do topo (Ponto 1 e 2), sendo esta localizada 3 metros acima do córrego Tucum. Para a retirada do material, foram utilizados tubos de PVC de cor escura com $55 \mathrm{~cm}$ de comprimento e $6 \mathrm{~cm}$ de largura. Após a coleta das amostras, estas foram recobertas com saco plástico de cor preta e encaminhadas para análise. As amostras retiradas de baixos terraços visaram à investigação da distribuição espacial das idades dos depósitos adjacentes ao canal e de momentos distintos de deposição, obedecendo à distância mínima de 70 centímetros do topo dos depósitos, a fim de evitar influências recentes de alteração antrópica ligadas ao uso da terra.

A análise granulométrica do material foi realizada no Laboratório de Solos da Faculdade de Engenharia Agrícola (FEAGRI) da Unicamp. Para tanto, foram coletadas cinco amostras nos mesmos locais de coleta do material para datação por LOE. As amostras foram analisadas pelo método da pipeta (CAMARGO et al., 1986), classificadas conforme a presença de areia muito grossa, areia grossa, areia média, areia fina, areia muito fina, silte e argila. A diferenciação granulométrica do material presente nos depósitos aluviais poderia permitir correlação entre a energia de transporte ao longo do córrego Tucum.

\section{Resultados e Discussão}

Datações efetuadas em áreas da Bacia Sedimentar do Paraná podem nos fornecer maior embasamento para elucidação da evolução morfoclimática nas Províncias geomorfológicas da Depressão Periférica Paulista e do Planalto Ocidental Paulista. Os depósitos datados em baixo terraço no curso inferior do córrego Tucum apresentaram idades Pleistocênicas-Holocênicas, com idades de $13400 \pm 2220$ e $18830 \pm 2150$ anos, em depósitos a 0,80 m e 1,00 m da superfície, respectivamente, em terraço com 4,5 metros de espessura.

Foram identificados também depósitos recentes ao longo do canal fluvial, distribuídos principalmente pelo alto e médio curso, com espessuras variando de $1 \mathrm{a}$ 1,5 metro, fazendo parte da atual dinâmica do córrego. As idades dos depósitos sedimentares correspondem a $3350 \pm 350$ e $2760 \pm 415$ anos no alto curso e a $3230 \pm 325$ anos no médio curso (Tabela 1). Esses terraços aluviais recentes podem corresponder a um novo pulso de modificação dos processos ao longo da bacia, regidos, provavelmente, por nova configuração climática, com consequente alteração no nível de base local.

A análise granulométrica dos materiais coletados nos terraços, nos mesmos pontos da coleta do material sedimentar para datação (LOE), indica marcante presença da fração areia nos depósitos associados ao córrego Tucum, com porcentagens superiores a 93\%, como no ponto 5, e a 98\%, no Ponto 2 (Tabela 2; Figura 2). 
Tabela 1: Dados obtidos das datações por LOE do material presente nos terraços fluviais.

\begin{tabular}{|c|c|c|c|}
\hline Amostras & Amostras Dose Anual $(\mu \mathrm{Gy} /$ ano) & Dose Acumulada (Gy) & Idade média/Anos \\
\hline Ponto 1 & $2.690 \pm 310$ & 36,0 & $13.400 \pm 2.220$ \\
\hline Ponto 2 & $2.840 \pm 180$ & 53,4 & $18.830 \pm 2.150$ \\
\hline Ponto 3 & $3.030 \pm 150$ & 9,8 & $3.230 \pm 325$ \\
\hline Ponto 4 & $3.250 \pm 180$ & 10,9 & $3.350 \pm 350$ \\
\hline Ponto 5 & $3.550 \pm 360$ & 9,8 & $2.760 \pm 415$ \\
\hline
\end{tabular}

Tabela 2: Dados de granulometria das amostras (g/kg).

\begin{tabular}{|c|l|l|l|l|l|l|l|l|}
\hline Amostras & \multicolumn{7}{|c|}{ Areia (\%) } & \multicolumn{2}{|c|}{} \\
\hline & $\begin{array}{l}\text { Muito } \\
\text { Grossa }\end{array}$ & Grossa & Média & Fina & $\begin{array}{l}\text { Muito } \\
\text { Fina }\end{array}$ & $\begin{array}{l}\text { Areia } \\
\text { Total }\end{array}$ & Argila & Silte \\
\hline Ponto 1 & 0,0 & 8,8 & 52,3 & 30,5 & 45,0 & 96,1 & 1,7 & 2,2 \\
\hline Ponto 2 & 0,0 & 4,8 & 52,5 & 36,1 & 50,0 & 98,4 & 1,4 & 2,0 \\
\hline Ponto 3 & 0,0 & 2,2 & 37,1 & 43,8 & 12,2 & 95,3 & 2,7 & 2,0 \\
\hline Ponto 4 & 0,0 & 0,0 & 17,2 & 61,4 & 15,9 & 94,5 & 2,8 & 2,7 \\
\hline Ponto 5 & 0.0 & 0,0 & 8,4 & 63,0 & 22,4 & 93,8 & 3,2 & 3,0 \\
\hline
\end{tabular}

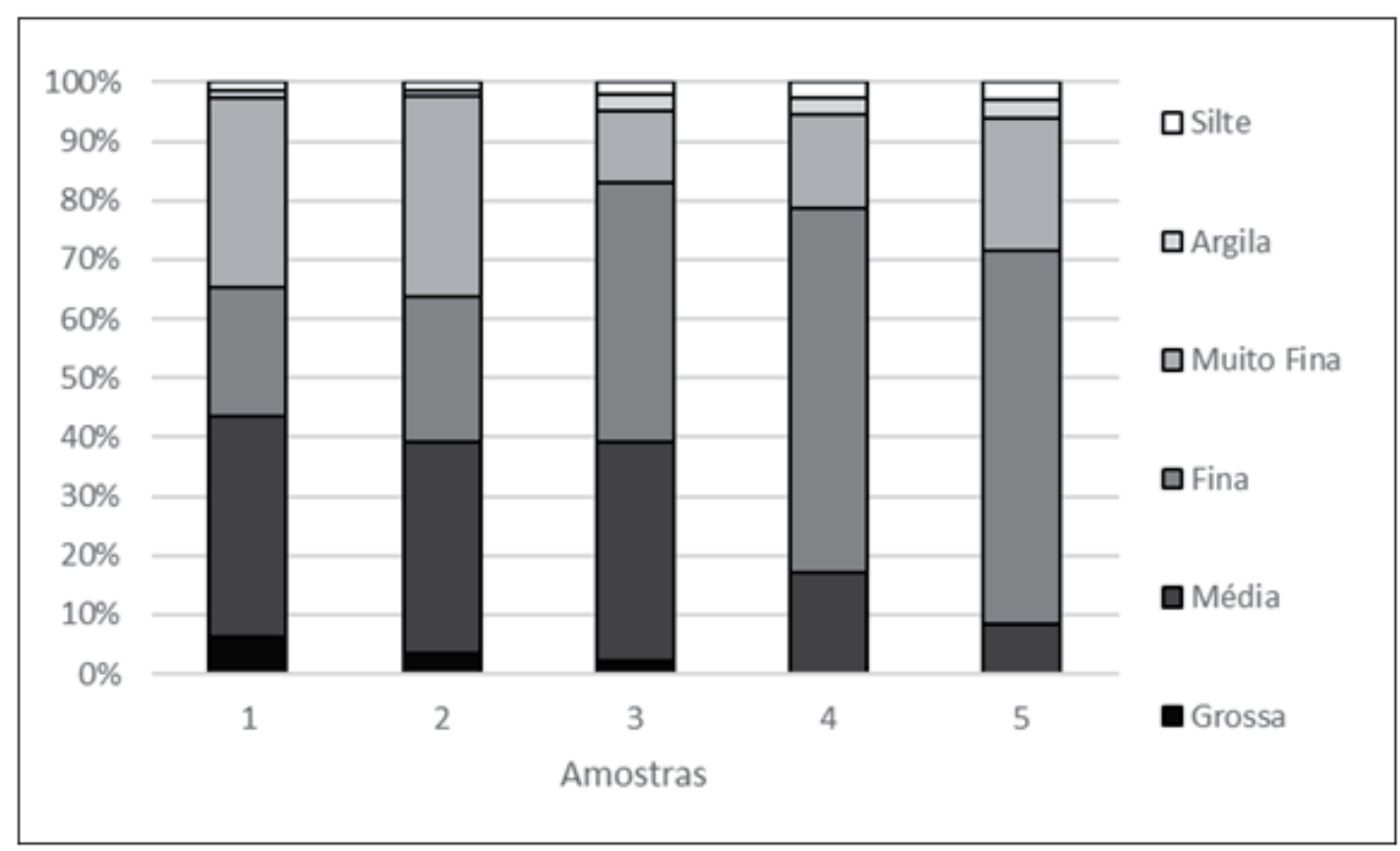

Figura 2: Gráfico referente às porcentagens das diferentes frações nas amostras.

A análise granulométrica dos depósitos aluviais associados ao canal permitiu associação direta com as condicionantes litológicas da área (Formação Pirambóia). O material arenoso de fração predominantemente média e fina e fundamentalmente composto por minerais primários, sobretudo quartzo, constitui o material de origem dos terraços e de parte dos solos locais, conforme aponta Oliveira (1997), dando a estes características de autoctonia.

Verificou-se também quantidade expressiva de materiais em suspensão, de acordo com coleta de duas amostras de água, em alto e baixo curso (Tabela 3). A discrepância entre o material particulado em alto e baixo curso aponta para o processo de sedimentação 
ao longo do canal. À medida que se dirige do alto para o baixo curso, parte deste material acaba sendo incorporado à carga de fundo e, consequentemente, aos bancos aluvionares, uma vez que o canal não possui energia suficiente para conduzir esse material até seu nível de base local.

Tabela 3: Dados referentes ao material particulado nas amostras de água (mg/L). Legenda: ST (Sólidos Totais), STF (Sólidos Totais Fixos), STV (Sólidos Totais Voláteis), SST (Sólidos Suspensos Totais), SSF (Sólidos Suspensos Fixos), SSV (Sólidos Suspensos Voláteis), SDT (Sólidos Dissolvidos Totais), SDF (Sólidos Dissolvidos Fixos), SDV (Sólidos Dissolvidos Voláteis).

\begin{tabular}{cccccccccc}
\hline Amostra & ST & STF & STV & SST & SSF & SSV & SDT & SDF & SDV \\
\hline Amostra 1 & 2149,0 & 1784,0 & 365,0 & 1490,0 & 1260,0 & 230,0 & 659,0 & 524,0 & 135,0 \\
\hline Amostra 2 & 389,0 & 327,0 & 62,0 & 378,0 & 321,0 & 57,0 & 11,0 & 6,0 & 5,0 \\
\hline
\end{tabular}

A entrada de material sedimentar arenoso no sistema fluvial é atribuída à ação conjunta dos fatores climático e litológico, potencializada ainda pela presença do fator antrópico, capaz de acelerar os processos erosivos e as transformações no canal do córrego Tucum. Quanto à gênese natural dos processos erosivos lineares, Perez Filho et al. (2011) apontam a característica litológica como fator desencadeante destes processos, tendo como destaque os depósitos coluviais arenosos com baixo grau de consolidação. Soma-se a isso a ação tectônica de ordem passiva (QUEIROZ NETO, 1973) e suas feições estruturais, que atuam no desenvolvimento de voçorocas nas áreas de cabeceira. Hasui et al. (1995) relatam também as descontinuidades presentes nas rochas das formações Corumbataí, Pirambóia/Botucatu e alguns depósitos coluviais que ocorrem devido a essas feições estruturais.

As voçorocas representariam formas capazes de recepcionar constantemente os fluxos superficiais, cuja percolação é favorecida pela permeabilidade dos materiais. Dessa forma, verifica-se que as descontinuidades e a orientação dessas feições no sentido NW-SE são de grande importância para a evolução dos processos de solapamento e de progressão erosiva.

Segundo Rocha (2009), mesmo em pequena escala de tempo, ajustamentos na morfologia do canal fluvial retratam uma reorganização de variáveis - condições de fluxo e carga sedimentar - para manutenção ou busca das condições de equilíbrio. Entendendo os rios como sistemas abertos, alterações morfológicas seriam respostas às modificações na entrada de matéria e/ou energia, autorregulando-se para evitar autodegradação ou sua total destruição. Questões como essas são plau- síveis ao observarmos as constantes transformações do córrego Tucum ao longo dos últimos cinquenta anos, constatadas por meio de fotografias aéreas de dois períodos distintos (1962 e 2000) e pela produção de perfis longitudinais (1978 e 2012).

O padrão do canal fluvial remonta à dinâmica dos bancos aluvionares presentes em seu leito. Ao observarmos as fotografias aéreas, foi possível constatarmos ciclicidade em suas distribuições, que permitiram classificar o canal, em sua maior parte, como entrelaçado. Esse padrão conjuga as discussões de canais múltiplos desenvolvidas por Leopold et al. (1964), Leopold e Wolman (1957), Candido (1971) e Christofoletti (1981), além das observações de Morisawa (1985). O padrão estabelecido entra em conformidade com a abordagem de Bridge (2002), relacionando-o a áreas onde a taxa de deposição é elevada, dando origem a bancos aluvionares (Figuras 3 e 4).

A formação de tais depósitos ao longo do canal permite inferência sobre a carga sedimentar disponível ao córrego Tucum, incapaz de mobilizá-los para além do seu exutório, fato comprovado pelo material particulado em suspensão nas amostras analisadas. Tais alterações no perfil longitudinal do canal permitiram inferir nova dinâmica de erosão, transporte e sedimentação ao longo do mesmo.

Ao analisarmos os perfis elaborados para o córrego Tucum (Figura 5), constatamos a dinâmica do canal em adaptar-se aos fatores físicos locais, como a entrada abundante da fração areia no sistema, que na escala temporal observada (1978 - 2012) demonstra constante busca de equilíbrio. Alterações realizadas no alto curso da bacia hidrográfica, principalmente relacio- 
Dinâmica Antrópica no Canal Fluvial do Córrego Tucum - São Pedro, São Paulo (Brasil)

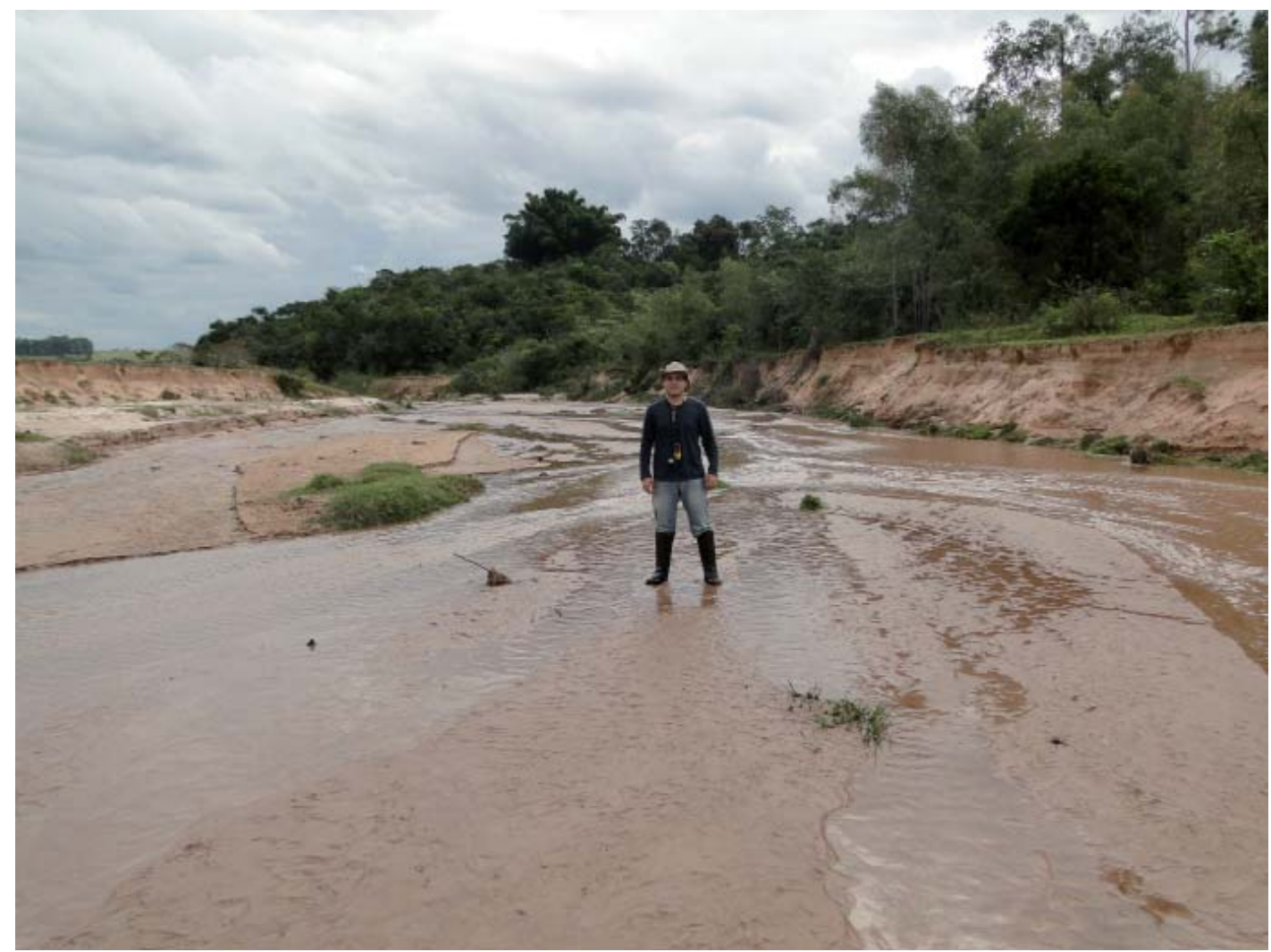

Figura 3 - Padrão entrelaçado presente em baixo curso do córrego Tucum. Foto: Diego Luciano do Nascimento.

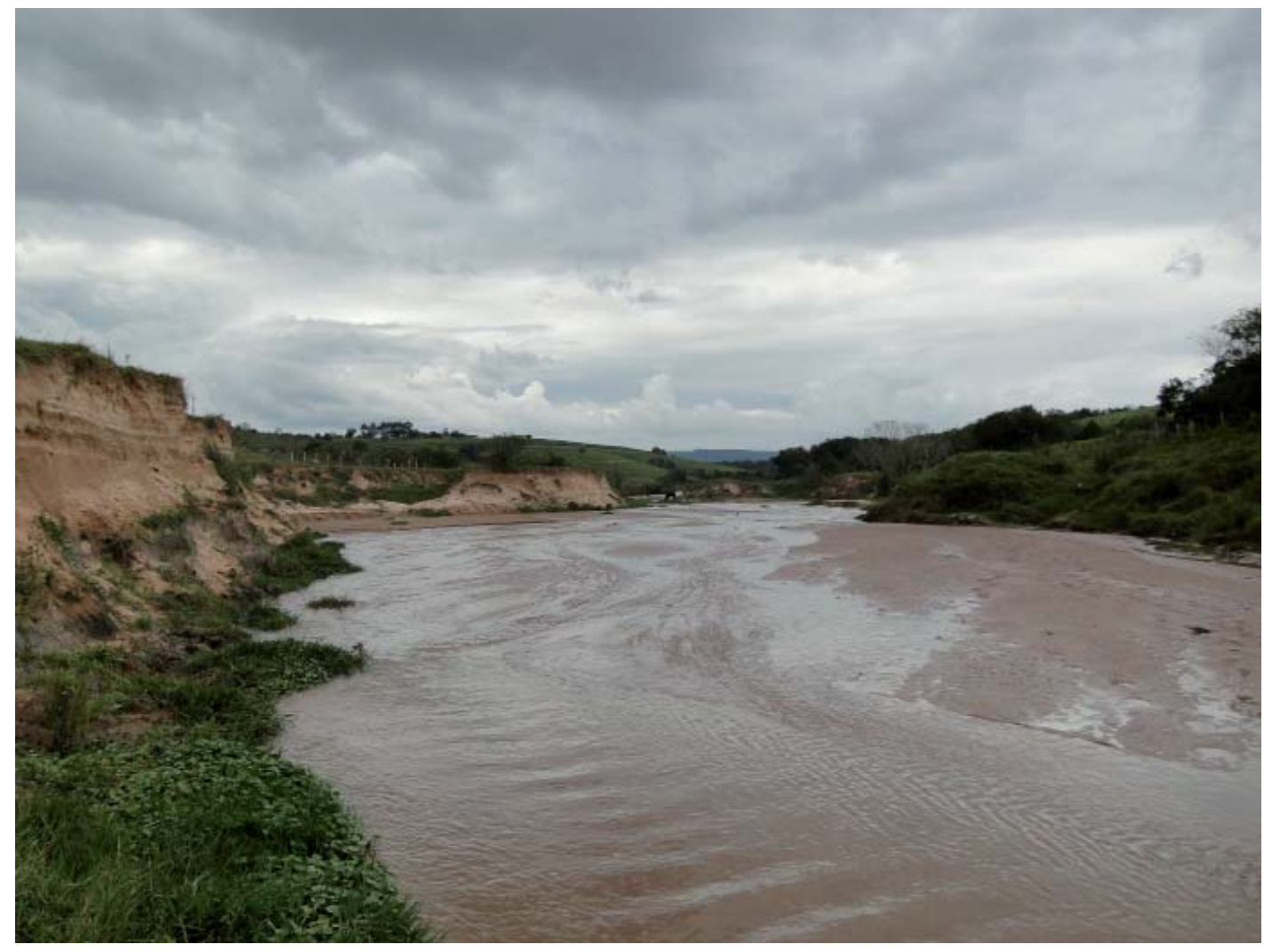

Figura 4 - Padrão entrelaçado presente em médio curso do córrego Tucum. Foto: Diego Luciano do Nascimento. 
nadas à urbanização, dentre eles a canalização do canal ao transpor a rodovia e a orientação do arruamento em direção às voçorocas, contribuíram efetivamente para as transformações ocorridas no perfil longitudinal do canal fluvial, como a elevação do curso próximo à sua foz e no trecho aferido no alto curso.

Segundo Mathias (2011), a bacia hidrográfica do Tucum passou por diversas intervenções ao longo das últimas décadas, em especial quanto a modificações no uso e na ocupação da terra. Em sua análise, concatenadas às nossas interpretações de uso no ano 1962, havia predomínio de pastagens na cabeceira (alto curso), o que motivara intensa atividade erosiva, com presença de sulcos, ravinas e voçorocas. Tal análise é verificada nas fotografias aéreas de 1962, dispostas em área de pastagem e vegetação rasteira (Figura 6).

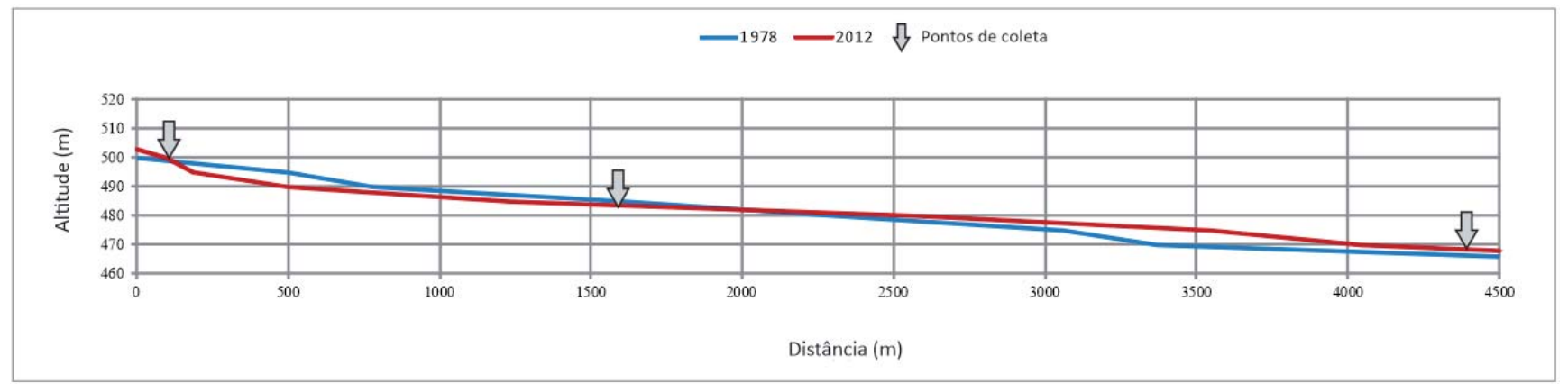

Figura 5 - Perfis longitudinais do córrego Tucum (referentes aos anos de 1978 e 2012).

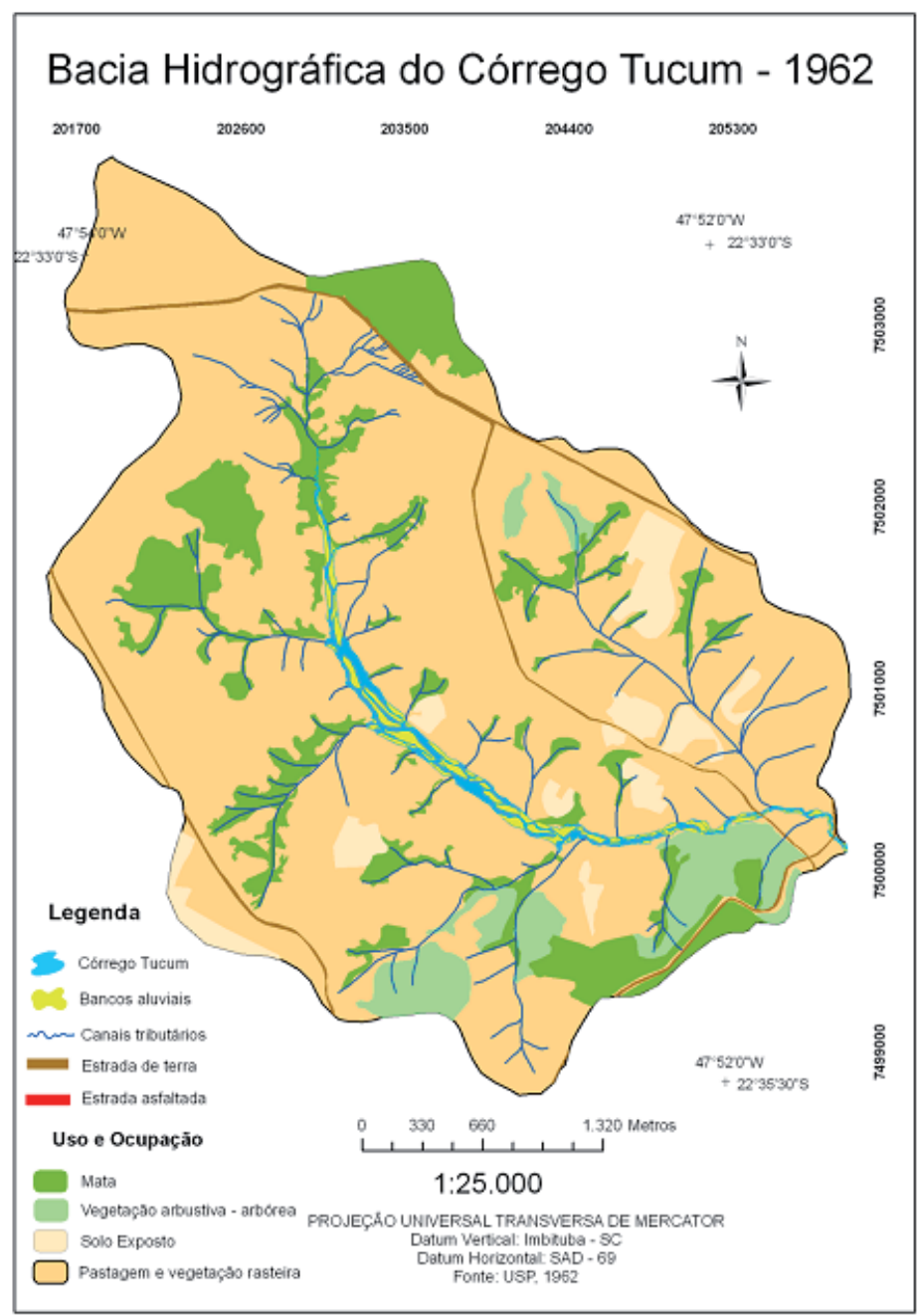

Figura 6 - Uso e ocupação da terra na bacia hidrográfica do córrego Tucum em 1962. 
De 1962 a 1986, ampliam-se as feições erosivas, assim como tem início a instalação de loteamentos urbanos na área. Entre os anos de 1986 e 1991, houve a tentativa de amenização das atividades erosivas, entretanto tais medidas foram insuficientes, culminando com a reativação dos processos. Mathias (2011) ainda destaca que nesse período parte da área de cabeceira correspondia a um antigo depósito de lixo.

Em 1992, foram realizadas obras para a contenção das feições erosivas, culminando com a instalação de galerias pluviais junto aos canais de primeira ordem da bacia como forma de conduzir o fluxo de água superficial. Além disso, houve o soterramento das voçorocas e ravinas situadas próximas aos interflúvios, pela técnica de terraceamento e fechamento do lixão.

De 1992 a 2000, verifica-se a ampliação da área urbana sobre as áreas antropicamente terraceadas, reativando incisões e dando origem a novos sulcos, ravinas e voçorocas. No período de 2000 a 2010, ocorrem a instalação de galerias pluviais e o asfaltamento dos bairros adjacentes. Conforme Mathias (2011), a pavimentação, entretanto, foi direcionada no sentido do declive, atuando como um forte agente na nova dinamização erosiva e preponderante no avanço da voçoroca do córrego Tucunzinho, tributário a montante do córrego Tucum (Figura 7).

A construção da rodovia Geraldo de Barros, que cruza perpendicularmente o córrego ainda no alto curso, pode ter sido um dos agentes reestruturadores do padrão do canal fluvial desde o início da década de 1970, contribuindo para alterações no balanço sedimentológico. $\mathrm{O}$ solo exposto presente nas cabeceiras, local de incidência de voçorocas, e a expansão urbana mais acentuada foram responsáveis pela nova configuração das formas aluvionares do canal fluvial e pela remodelação do perfil longitudinal. $\mathrm{O}$ aumento dos bancos arenosos reflete

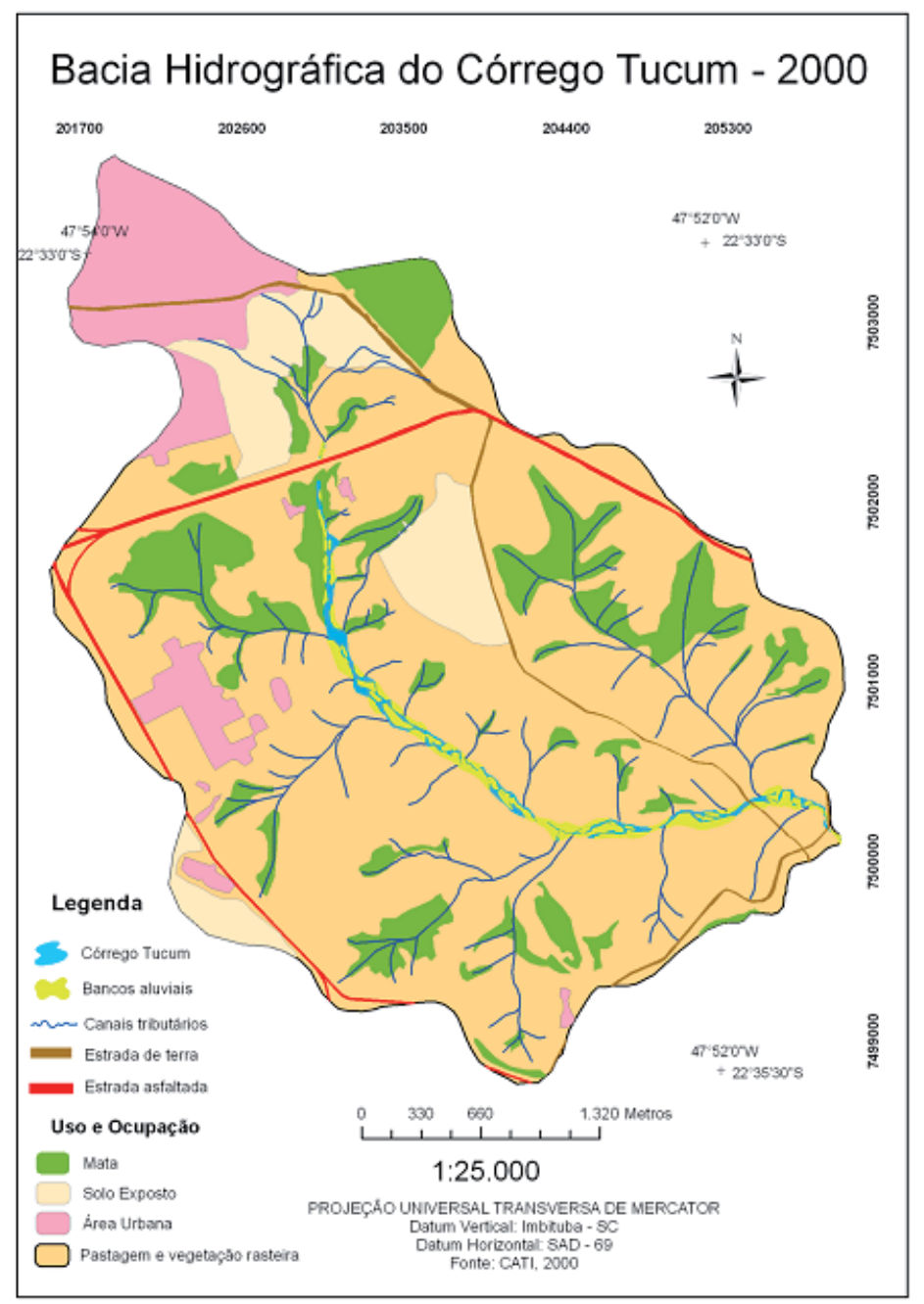

Figura 7: Uso e ocupação da terra na bacia hidrográfica do córrego Tucum, em 2000. 
tanto as transformações de uso e ocupação da terra no decorrer das últimas décadas, como o trabalho do canal fluvial na tentativa de se equilibrar longitudinalmente.

A comparação dos perfis elaborados permite fazermos inferências sobre essa nova dinâmica estabelecida, cujos reflexos se apresentam no comportamento do canal fluvial. Tomando como base o perfil ideal - exprimindo conformação logarítmica com concavidade para cima e assíntotas longas - , notamos que nenhum dos perfis construídos relata proeminência de zonas anômalas, justificando a presença de litologia una e ação neotectônica como um fator secundário em sua conformação.

O perfil longitudinal elaborado a partir de dados obtidos em campo permitiu observar maior uniformidade do córrego no médio curso, decorrente, provavelmente, da instalação de nível de base efêmero, ligado à presença de leito de rocha arenítica pouco alterada da Formação Pirambóia em pequeno trecho, no médio curso.

Quanto à obra para passagem de água pela rodovia Geraldo de Barros, tida como nível de base local e causadora de transformações das formas do canal, tem-se mostrado como variável de alteração de balanço sedimentar, confirmada pela elevação de três metros do perfil atual quando comparado aos dados do perfil com base na carta topográfica.

As precipitações pluviométricas no período de análise poderiam ser determinantes para alguma modificação das formas aluvionares atuais do canal do córrego Tucum. Sua distribuição nos meses mais chuvosos se dá irregularmente, concentrando maiores volumes em poucos dias, suficientes para mobilizar carga sedimentar junto ao canal fluvial. As médias de $1400 \mathrm{~mm} /$ ano permaneceram quase que constantes ao longo do período de análise relacionado à ação do fator antrópico, com exceção dos extremos: 737,30 mm em 1968 e 2227,60 mm em 1983. Em fevereiro de 1995, a precipitação de 651,1 mm culminou, no mês de março, com o rompimento do aterro no qual passava a rodovia Geraldo de Barros, conforme aborda Ferreira (2004) e expresso no banco de dados hidrológicos do DAEE.

O nível de base, elevado em dois metros na foz, quando comparado ao ano de 1978, é outro indicativo de constante alteração do canal fluvial na busca de seu equilíbrio dinâmico, o que se verificaria entre o limiar do material fornecido pelos agentes erosivos e o eliminado para o canal subsequente.

Segundo Carpi Junior (1996), a implantação de portos de areia à margem do canal fluvial do córrego Tucum, localizado no alto curso, com extração contínua de areia, provocou rebaixamento constante da calha fluvial, possibilitando o reajustamento do nível de base. Os resultados encontrados nos permitem concluir que, mesmo com a extração de material sedimentar do leito, a intensa e contínua entrada do mesmo para o canal fluvial foi suficiente para elevar em 2 metros o nível de base local junto à confluência com o ribeirão Araquá.

Assim, tomando como base as modificações no canal fluvial do córrego Tucum, observou-se a manutenção de um canal próximo do padrão entrelaçado. Porém houve alterações nos bancos aluvionares ao longo desses anos, inclusive com formação de pequenos trechos retilíneos, por conta do contato direto com o arcabouço litológico, fator este confirmado na elaboração do perfil longitudinal e em trabalho de campo.

Quanto às formas presentes no sistema fluvial, podemos atribuí-las a dois períodos de formação: um relacionado ao aspecto climático, com transformações ocorridas ao longo do Pleistoceno Superior/Holoceno, e outro decorrente das dinâmicas pré-atuais, nas quais se insere o fator antrópico.

Os depósitos aluviais datados por Sallun e Suguio (2006) nas bacias hidrográficas do rio Santo Anastácio e do rio Aguapeí apontam para idades de aproximadas de 18.000 e 14.000 anos, muito próximas às encontradas no terraço aluvial do córrego Tucum. Outra correspondência importante a ser destacada, apresentada por Ponçano e Prandini (1987), diz respeito ao período glacial Wurm, ocorrido há cerca de 15.000 anos A.P.. Ainda segundo os autores, durante esse período teria vigorado um clima seco, capaz de atenuar processos erosivos semelhantes a voçorocamentos em diversas partes da Depressão Periférica. A idade de 13.500 anos do terraço datado poderia ser resultante do mesmo processo e da passagem para um clima quente e úmido que, com o entalhamento do talvegue, passa a ser identificado na paisagem. No tocante às oscilações climáticas, deixamos claro que a correspondência em níveis escalares de bacia sedimentar, ou mesmo de províncias geomorfológicas, é muito cautelosa, uma vez que os procedimentos avaliativos dos autores supracitados não foram totalmente aplicados ao nível do canal estudado.

A presença de baixos terraços fluviais ao longo do 
córrego Tucum se relaciona às transformações no tempo da natureza, evidenciando modificações nos processos de esculturação do relevo. A formação destas pode estar atrelada à dinâmica glacial e interglacial que se sucedeu ao longo do Pleistoceno Superior.

Datações em diferentes níveis nos terraços do córrego Tucum demonstram um ritmo de evolução pretérito condizente com aqueles efetivados pelo fator climático. Os depósitos mais antigos, localizados no baixo curso, próximos da confluência com o ribeirão Araquá, datam de aproximadamente 13.500 anos (amostra coletada a $80 \mathrm{~cm}$ da superfície) e 18.000 anos (amostra coletada a $100 \mathrm{~cm}$ da superfície).

O entalhamento do canal foi capaz de expor esses materiais. Assim, pode-se pressupor a existência de uma relação entre as idades absolutas e as mudanças de cunho climático, conforme mostram estudos de outros locais por meio da LOE e de outros marcadores ambientais (LEDRU, 1993; STEVAUX, 1994; LEDRU et al., 1996; STEVAUX, 2000; SALLUN e SUGUIO, 2006), apontando decréscimos de umidade ao final do Pleistoceno (16.000 a 11.000 A.P) e climas mais secos também no Holoceno tardio (entre 3.500 a 1.500 A.P).

Estudos realizados por Latrubesse et al. (2005) confirmam a complexidade em estabelecer tipologias de canais fluviais em regimes tropicais úmidos e, em muitos casos, parece ser mais coerente estabelecer apenas a divisão de canais únicos e múltiplos. Assim, o córrego Tucum se comportaria como canal fluvial múltiplo, apresentando trechos retilíneos e entrelaçados.

\section{Considerações Finais}

Modificações dos depósitos aluviais ao longo do córrego Tucum evidenciam a dinamicidade do sistema fluvial no qual está inserido, levando-se em consideração as condições físico-naturais e antrópicas às quais está agora submetido. O homem passa a exercer papel catalisador nos processos físicos locais pela sua capacidade de introduzir novos arranjos nos fluxos de matéria e energia - no caso, pelo processo de urbanização das áreas de cabeceiras - e, assim, reorganizar o sistema e levá-lo a uma nova busca pelo equilíbrio dinâmico, como ocorre no processo de urbanização de interflúvios e encostas de bacias hidrográficas.

O fator antrópico, aliado aos atributos naturais da área em questão, foi suficientemente capaz de condicio- nar o canal fluvial do córrego Tucum a buscar novos arranjos de seu curso e novas feições adjacentes. Levando em consideração a escala geomorfológica aqui adotada, o entendimento das modificações de curto termo está ligado diretamente a determinadas variáveis potencializadas pelas modificações de uso da terra na bacia. Além disso, indicações de um cenário muito mais complexo, ligado às oscilações climáticas pleistocênicas e holocênicas, não pode aqui ser precisado, ficando maiores explanações dessas modificações em cenário regional ligadas aos autores já citados. Datações absolutas pelo método de luminescência opticamente estimulada em materiais sedimentares foram importantes para análise das variáveis naturais, e a ação antrópica poderá influenciar tais sistemas ao longo do tempo.

\section{Agradecimentos}

Externamos nossos agradecimentos à FAPESP (Fundação de Amparo à Pesquisa do Estado de São Paulo), pela viabilização financeira da pesquisa (Processo n. 2011/19585-3).

\section{Referências Bibliográficas}

AITKEN, M. J.; SMITH, B. W. Optical dating: recuperation after bleaching. Quaternary Science Reviews, vol. 7, p. 387393, 1988.

AITKEN, M. J. Optical Dating. Quaternary Science Reviews, vol. 11, p. 127-131, 1992.

ALMEIDA, F. F. M. Fundamentos geológicos do relevo paulista. Boletim Instituto de Geografia e Geologia - IGG-USP, São Paulo, vol. 41, 1964.

BRIDGE, J. S. Rivers and Floodplains: forms, processes, and sedimentary. Oxford, UK: Blackwell Science, 2002.

BRIDGLAND, D.; WESTAWAY, R. Climatically controlled river terrace staircases: A worldwide Quaternary phenomenon. Geomorphology, vol. 98, n. 3, p. 285-315, 2008.

CAMARGO, O.A.; MONIZ, A. C.; JORGE, J.A.; VALADARES, J. M. A. S. Métodos de análise química, mineralógica e física de solos do Instituto Agronômico de Campinas (IAC, Boletim Técnico, 106). Campinas: Instituto Agronômico de Campinas, 1986.

CANDIDO, A. J. Contribuição ao estudo dos meandramentos fluviais. Notícia Geomorfológica, vol. 11, n. 22, p. 21-38, 1971. 
CARPI JUNIOR, S. Técnicas cartográficas aplicadas à dinâmica da bacia do Ribeirão Araquá - SP. Dissertação (Mestrado em Geografia) - Instituto de Geociências e Ciências Exatas, Universidade Estadual Paulista "Júlio de Mesquita Filho”, Rio Claro, 1996.

CHRISTOFOLETTI, A. Geomorfologia Fluvial. São Paulo: Edgard Blucher, 1981.

CONTI, J. B. Condições climáticas da região das Águas de São Pedro (SP). Caderno de Ciências da Terra, vol. 11, p. 01-13, 1971.

CUNHA, S. B. da. Geomorfologia Fluvial. In: Geomorfologia: uma atualização de bases e conceitos; GUERRA, A. J. T.; CUNHA, S. B. da. (orgs.). 3 ed. Rio de Janeiro: Bertrand Brasil, 1998.

FERREIRA, M. D. Análise da evolução dos processos erosivos acelerados em áreas urbanas e das técnicas de controle e recuperação - córrego do Tucum (São Pedro/SP). Dissertação (Mestrado em Geotecnia) - Escola de Engenharia de São Carlos, Universidade Federal de São Carlos, São Carlos, 2004.

FERREIRA, S. R.; CHANG, M. R. C. Datação das Formações Rio Claro e Piraçununga por termoluminescência. Revista da Escola de Minas, vol. 61, n. 2, p. 129-134, 2008.

GIBBARD, P. L.; LEWIN, J. River incision and terrace formation in the Late Cenozoic of Europe. Tectonophysics, vol. 474, n. 1, p. 41-55, 2009.

HASUI, Y.; FACINCANI, E. M.; SANTOS, M. dos; JIMÉNEZRUEDA, J. R. Aspectos estruturais e neotectônicos na formação de boçorocas na região de São Pedro, SP. Revista Geociências, vol.14, n. 2, p.59-76, 1995.

HUNTLEY, D. J.; GODOFREY-SMITH, D. I.; THEWALT, M. L. W. Optical Dating of Sediments. Nature, London, p. 105-107, 1985.

LATRUBESSE, E. M.; STEVAUX, J. C.; SINHA, R. Grandes sistemas fluviais tropicais: uma visão geral. Revista Brasileira de Geomorfologia, v.6, n.1, p. 1-18, 2005.

LEDRU, M.P. Late Quaternary environmental and climatic changes in Central Brazil. Quaternary Research, v. 39, p. 90-98, 1993.

LEDRU, P. M; BRAGA, P. I. S.; SOUBIÈS, F.; FOURNIER, M.; MARTIN, L.; SUGUIO, K.; TURCQ, B. The last 50.000 years in the Neotropics (Southern Brazil): evolution of vegetation and climate. Paleogeography, Paleoclimatology, Paleocology, v. 123, p. 239-257, 1996.
LEOPOLD, L. B.; WOLMAN, M. G. River Channel Patterns: Braided, Meandering and Straight. Geological Survey Professional Paper 282-B. Washington: United States Government Printing Office, 1957.

LEOPOLD, L. B.; WOLMAN, M. G.; MILLER, J. P. Fluvial processes in Geomorphology. São Francisco: W. H. Freeman and Company, 1964.

LITCHFIELD, N. J.; BERRYMAN, K. R. Correlation of fluvial terraces within the Hikurangi Margin, New Zeland: implications for climate and baselevel controls. Geomorphology, vol. 68, n. 3, p. 291-313, 2005.

LOPES, R. da C.; MARCONATO, A. Formação Pirambóia. Mapa Geológico do Estado de São Paulo (1:750.000): breve descrição das unidades litoestratigráficas aflorantes no Estado de São Paulo. Serviço Geológico do Brasil - CPRM, 2006.

MATHIAS, D. T. Proposta de recuperação de áreas periurbanas erodidas com base em parâmetros hidrológicos e geomorfológicos: córrego Tucunzinho (São Pedro/SP). Dissertação (Mestrado em Geografia) - Instituto de Geociências e Ciências Exatas, Universidade Estadual Paulista "Júlio de Mesquita Filho”, Rio Claro, 2011.

MORISAWA, M. Rivers: form and process. Geomorphology texts, 7. New York: Longman Group Limited, 1985.

OLIVEIRA, J. B.; PRADO, H. Carta pedológica Semidetalhada do Estado de São Paulo. Folha de Piracicaba, (escala 1:100.000). Campinas: Instituto Agronômico; Instituto Geográfico e Cartográfico, 1989.

OLIVEIRA, D. de. Estudo macro e micromorfológico de uma topossequência na bacia do Córrego do Retiro em São PedroSP. Dissertação (Mestrado em Geografia Física) - Faculdade de Filosofia, Letras e Ciências Humanas, Universidade de São Paulo, São Paulo, 1997.

PENTEADO, M. M. Geomorfologia do setor centroocidental da Depressão Periférica Paulista. Tese (Doutorado em Geografia) - Instituto de Geociências e Ciências Exatas, Universidade Estadual Paulista “Júlio de Mesquita Filho”, Rio Claro, 1968.

PEREZ FILHO, A.; CARPI JUNIOR, S.; QUARESMA, C. C. Gestão pública e riscos ambientais relacionados a processos erosivos: caso de São Pedro, São Paulo, Brasil. Territorium, vol. 18, p. 219-226, 2011.

PONÇANO, W. L.; PRANDINI, F. L. Boçorocas no Estado de São Paulo: uma revisão. Anais do $4^{\circ}$ Simpósio Nacional de Controle de Erosão. Marília: ABGE/DAEE, p. 149-177, 1987. 
QUEIROZ NETO, J. P. de. O Simpósio sobre o Quaternário do Brasil de Sudeste: setembro de 1971. Caderno de Ciências da Terra, vol. 31, 1973.

ROCHA, P. C. Os processos geomórficos e o estado de equilíbrio fluvial no alto Rio Paraná, centro sul do Brasil. Revista Geosul, vol. 24, n. 48, p. 153-176, 2009.

ROSGEN, D. L. A classification of natural rivers. Catena, v. 22, p. 169-199, 1994.

SALLUN, A. E. M.; SUGUIO, K. Depósitos Quaternários da região de entre Marília e Presidente Prudente (SP). Revista brasileira de Geociências, vol. 36, n. 3, p.385-395, 2006.

SÃO PAULO (Estado). Secretaria de Economia e Planejamento. Coordenadoria de Ação Regional. Divisão de Geografia. Águas de São Pedro I: SF-23-Y-A-IV-I-NO-F, 1979.

SÃO PAULO (Estado). Secretaria de Economia e Planejamento. Coordenadoria de Ação Regional. Divisão de Geografia. Águas de São Pedro II: SF-23-Y-A-IV-1-NE-E, 1979.

SÃO PAULO (Estado). Secretaria de Economia e Planejamento. Coordenadoria de Ação Regional. Divisão de Geografia. Ribeirão do Grama: SF-23-Y-A-IV-1-NE-C, 1979.
SÃO PAULO (Estado). Secretaria de Economia e Planejamento. Coordenadoria de Ação Regional. Divisão de Geografia. São Pedro III: SF-23-Y-A-IV-1-NO-D, 1979.

STEVAUX J. C. O rio Paraná: geomorfogênese, sedimentação e evolução quaternária do seu curso superior (região de Porto Rico, PR). (Doutorado em Geografia Física) - Faculdade de Filosofia, Letras e Ciências Humanas, Universidade de São Paulo, São Paulo, 1993.

STEVAUX J. C. The Upper Paraná River (Brazil): geomorphology, sedimentology and paleoclimatology. Quaternary International, vol. 21, p. 143-161, 1994.

STORANI, D. L.; PEREZ FILHO, A. Novas informações sobre geocronologia em níveis de baixo terraço fluvial do rio Mogi Guaçu, SP, Brasil. Revista Brasileira de Geomorfologia, v. 16, n. 2, p. 191-199, 2015.

SUGUIO, K.; BIGARELLA, J. J. Ambiente Fluvial. Curitiba: Editora da Universidade Federal do Paraná, 1979.

TATUMI, S. H.; GOZZI, G.; YEE, M.; OLIVEIRA, V. I. de; SALLUN, A. E. M.; SUGUIO, K. Luminescence dating of Quaternary deposits in geology in Brazil. Radiation Protection Dosimetry, vol. 19, n. 1-4, p. 462-469, 2006. 